\title{
Frequency of chest pain in primary care, diagnostic tests performed and final diagnoses
}

Citation for published version (APA):

Hoorweg, B. B. N., Willemsen, R. T. A., Cleef, L. E., Boogaerts, T., Buntinx, F., Glatz, J. F. C., \& Dinant, G. J. (2017). Frequency of chest pain in primary care, diagnostic tests performed and final diagnoses. Heart, 103(21), 1727-1732. https://doi.org/10.1136/heartjnl-2016-310905

Document status and date:

Published: 01/11/2017

DOI:

10.1136/heartjnl-2016-310905

Document Version:

Publisher's PDF, also known as Version of record

Document license:

Taverne

Please check the document version of this publication:

- A submitted manuscript is the version of the article upon submission and before peer-review. There can be important differences between the submitted version and the official published version of record.

People interested in the research are advised to contact the author for the final version of the publication, or visit the DOI to the publisher's website.

- The final author version and the galley proof are versions of the publication after peer review.

- The final published version features the final layout of the paper including the volume, issue and page numbers.

Link to publication

\footnotetext{
General rights rights.

- You may freely distribute the URL identifying the publication in the public portal. please follow below link for the End User Agreement:

www.umlib.nl/taverne-license

Take down policy

If you believe that this document breaches copyright please contact us at:

repository@maastrichtuniversity.nl

providing details and we will investigate your claim.
}

Copyright and moral rights for the publications made accessible in the public portal are retained by the authors and/or other copyright owners and it is a condition of accessing publications that users recognise and abide by the legal requirements associated with these

- Users may download and print one copy of any publication from the public portal for the purpose of private study or research.

- You may not further distribute the material or use it for any profit-making activity or commercial gain

If the publication is distributed under the terms of Article $25 \mathrm{fa}$ of the Dutch Copyright Act, indicated by the "Taverne" license above, 


\title{
Frequency of chest pain in primary care, diagnostic tests performed and final diagnoses
}

\author{
Beatriijs BN Hoorweg, ${ }^{1}$ Robert TA Willemsen, ${ }^{1}$ Lotte E Cleef, ${ }^{1}$ Tom Boogaerts, ${ }^{2}$ \\ Frank Buntinx, ${ }^{1,2}$ Jan FC Glatz, ${ }^{3}$ Geert Jan Dinant ${ }^{1}$
}

- Additional material is published online only. To view please visit the journal online (http://dx.doi.org/10.1136/ heartjnl-2016-310905).

${ }^{1}$ Department Family Medicine, Maastricht University, Maastricht, The Netherlands ${ }^{2}$ Department Family Medicine, KU Leuven, Leuven, Belgium ${ }^{3}$ Department of Genetics and Cell Biology, Maastricht University, Maastricht, The Netherlands

\section{Correspondence to} Dr Robert TA Willemsen, Department Family Medicine, Maastricht University, P. Debyeplein 1, PO Box 616, 6200 MD Maastricht, The Netherlands; robert.willemsen@ maastrichtuniversity.nl

Received 14 November 2016 Revised 22 March 2017 Accepted 29 March 2017

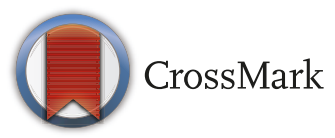

To cite: Hoorweg BBN,

Willemsen RTA,

Cleef $\mathrm{LE}$, et al. Heart

2017:103:1727-1732.

\section{ABSTRACT}

Objective Observational study of patients with chest pain in primary care: determination of incidence, referral rate, diagnostic tests and (agreement between) working and final diagnoses.

Methods 118 general practitioners (GPs) in the Netherlands and Belgium recorded all patient contacts during 2 weeks. Furthermore, patients presenting with chest pain were registered extensively. A follow-up form was filled in after 30 days.

Results 22294 patient contacts were registered. In 281 $(1.26 \%)$, chest pain was a reason for consulting the GP (mean age for men 54.4/women 53 years). In this cohort of 281 patients, in $38.1 \%$ of patients, acute coronary syndrome (ACS) was suspected at least temporarily during consultation, $40.2 \%$ of patients were referred to secondary care and 512 diagnostic tests were performed by GPs and consulted specialists. Musculoskeletal pain was the most frequent working (26.1\%) and final diagnoses (33.1\%). Potentially life-threatening diseases as final diagnosis (such as myocardial infarction) accounted for $8.4 \%$ of all chest pain cases. In $23.1 \%$ of cases, a major difference between working and final diagnoses was found, in $0.7 \%$ a severe disease was initially missed by the GP.

Conclusion Chest pain was present in 281 patients (1.26\% of all consultations). Final diagnoses were mostly non-life-threatening. Nevertheless, in $8.4 \%$ of patients with chest pain, life-threatening underlying causes were identified. This seems reflected in the magnitude and wide variety of diagnostic tests performed in these patients by GPs and specialists, in the (safe) overestimation of life-threatening diseases by GPs at initial assessment and in the high referral rate we found.

\section{INTRODUCTION}

In primary care, general practitioners (GPs) are faced with a considerable number of patients presenting with chest pain of recent onset $(0.7 \%$ $2.7 \%$ of all GP consultations). ${ }^{1-3}$ Underlying causes vary widely. Life-threatening conditions as acute coronary syndrome (ACS) are identified as a cause in populations with chest pain in primary care in $1.5 \%$ (unselected chest pain patients) to $22 \%$ (in patients with chest pain suspected of ACS) of all cases. ${ }^{45}$ However, these severe diseases are outnumbered by minor conditions with an advantageous course (mild respiratory, gastrointestinal, musculoskeletal or psychiatric causes). ${ }^{6}$ For GPs, distinguishing life-threatening causes from mild conditions, in order to minimise both over-referrals and missed cases, is of main importance. ${ }^{7} 8$ However, distinction between mild and life-threatening disease is challenging in primary care, due to overlapping signs and symptoms and early or atypical presentations. ${ }^{9-13}$

In literature, several studies have presented final diagnoses of chest pain in patients presenting in primary care. ${ }^{4}$ However, less serious final diagnoses fail to reflect potential doubts by GPs earlier in the diagnostic process. By means of a registry study, we aimed (1) to examine the current incidence of chest pain in primary care in the Netherlands and Belgium. Moreover, we aimed to describe several other aspects of chest pain that are meaningful to GPs, secondary care physicians and researchers in the field: (2) the relative number of cases where ACS is at least temporarily considered by the GP during consultation, (3) number and types of diagnostic tests performed, (4) the overall referral rate, (5) the working diagnoses at presentation, (6) the final diagnoses after 30 days and (7) comparison of working and final diagnoses.

\section{METHODS}

We performed a prospective registry study on the occurrence of chest pain in primary care in the Netherlands and Belgium. GPs were invited by email to participate. During the registration period, participating GPs registered numbers of all patient contacts (consultations, home visits and telephone consultations) in the daytime during a 2-week period between August and December 2015 (Belgium), and April and June 2016 (The Netherlands). For the proportion of patients with a new episode of chest pain-defined as a painful, uncomfortable, stuffy or tight sensation on the sternum or anterior chest wall, with allowance of inclusion of new episodes of chest pain in patients with a history of coronary artery disease and without specific limitation for the duration of complaints - the following additional issues were registered on first assessment by their GP: type of contact, consideration of ACS, additional diagnostic tests at or directly after assessment, working diagnosis and referral policy. After 30 days, GPs registered: final diagnosis, diagnostic tests performed after first assessment, (duration of) hospitalisation and death. All individual patients were included only once. Data were registered on case report forms with multiple-choice answers to all studied issues. GPs were instructed by email and the registration form was self explanatory. 


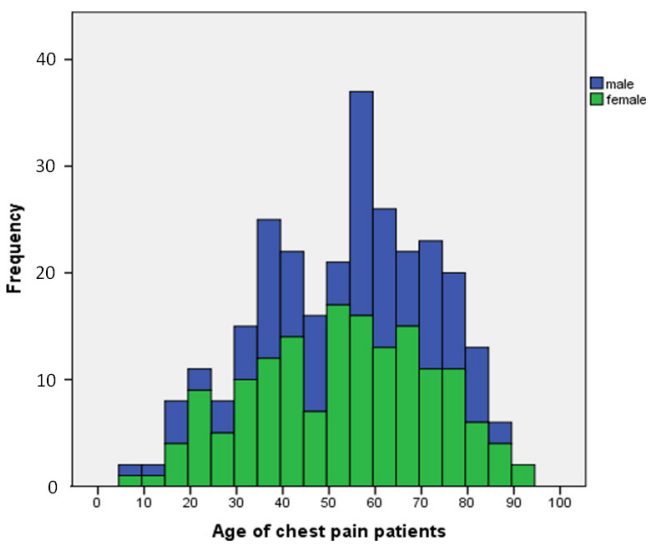

Figure 1 Frequency histogram of age and sex among patients with chest pain ( $n=279$, two cases missing). Of all 281 patients with chest pain, 121 (43.1\%) were male (mean age 54.4years), $158(56.2 \%)$ were female (mean age 53.0 years), in two cases sex was unknown.

Working and final diagnoses were classified by the authors (RW and TB) using the international classification of primary care (ICPC) coding system. For each diagnosis, the system provides a unique combination of a capital letter (to indicate the organ tract specific main category) and a number (to indicate the specific diagnosis), For example, K75.00 for 'cardiac: myocardial infarction'. In our study, working and final diagnoses were both registered as a complete ICPC-coded diagnosis (capital letter and number) and an organ tract-specified diagnosis only (capital letter only, eg, $\mathrm{K}$ for cardiac, $\mathrm{R}$ for respiratory, D for gastro-intestinal, $\mathrm{P}$ for psychogenic and $\mathrm{L}$ for musculoskeletal diagnoses). (Dis)agreement between working and final diagnoses was classified in each case as 'equal' (identical ICPC-code for working and final diagnoses), 'minor difference' (minor difference in ICPC-code) or 'major difference' (difference in ICPCcode with expected consequences for the diagnostic and/or therapeutic course of the patient).

Besides, all diagnoses were classified as either life-threatening disease or non-life-threatening disease. A life-threatening disease was defined as cardiac ischaemic disease, pulmonary embolism, aortic aneurysm, pneumothorax, major haemorrage, acute life-threatening abdominal disease and ventricular rhythm disorders. Both working and final diagnosis regularly consisted of more than one optional diagnosis. In these cases, only the first disease was used for classification, except in cases where life-threatening diseases were mentioned among further (working) diagnoses. In that case, the life-threatening disease

Table 1 Frequency (in absolute numbers) of different incidences of chest pain per GP $(n=118)$

\begin{tabular}{ll}
\hline Incidence of chest pain, \% & No of GPs $(\mathbf{n}=118)$ \\
\hline 0 & 22 \\
$0-1$ (larger than 0$)$ & 39 \\
$1-2$ & 31 \\
$2-3$ & 15 \\
$3-4$ & 6 \\
$4-5$ & 4 \\
$5-6$ & 0 \\
$6-7$ & 1 \\
\hline
\end{tabular}

Incidence of chest pain per GP varied from $0.0 \%$ to $6.62 \%$ of total consultations per GP (mean incidence per GP 1.32 ( \pm SD 1.20), median 0.95).

$\mathrm{GPs}$, general practitioners was used. All statistical analyses were calculated using SPSS 23. Differences in proportion between groups were verified using the $\chi^{2}$ test or Fisher's exact test, if appropriate. Differences were considered significant if the $\mathrm{p}$ value was below 0.05 .

This study was approved by the Ethical Review Boards of University Hospital Leuven and Maastricht University. Regular care was not affected by the study. Signed consent was not required.

\section{RESULTS}

\section{Patient numbers, incidence}

(Types of) contacts

One thousand six hundred and thirteen GPs were invited to participate, 134 GPs (8.3\% of all invited GPs) agreed, accounting for $0.5 \%$ of all registered GPs in the Netherlands and Belgium. Nationwide, 118 GPs (71 Dutch and 47 Belgian) returned the registration form and recorded 22294 patient contacts during the 2-week period. The mean number of patient contacts per GP was 189 (209 per Dutch and 158 per Belgian GP). Types of contacts of all consultations were only registered by the Dutch GPs. The 14862 Dutch patient contacts consisted of 10477 consultations (70.5\%), 908 home visits (6.1\%) and 3477 telephone consultations (23.4\%).

\section{Chest pain: incidence}

Chest pain as reason for encounter or at least substantial topic during the encounter occurred in 281 of 22294 contacts (in the Netherlands 160 patients, in Belgium 121 patients; 249 were consultations (88.6\%), 23 were home visits $(8.2 \%)$ and 8 were telephone contacts $(2.8 \%)$, one type of contact was unknown). The incidence of chest pain as a reason for encounter overall was $1.26 \%(1.08 \%$ in the Netherlands and $1.63 \%$ in Belgium, $\mathrm{p}<0.0005)$. Incidence of chest pain per GP varied from $0.0 \%$ to $6.62 \%$ of total consultations per GP. Mean incidence per GP was 1.32 ( \pm SD 1.20, SEM 0.11), median 0.95 (table 1$)$. Chest pain occurred more $(p=0.03)$ in women $(158 / 279$ cases $(56.6 \%)$, mean age 54.4 years) than in men $(121 / 279(43.4 \%)$, mean age 53.0 years). In two cases, sex was unknown (figure 1).

\section{GPs' first assessment at presentation \\ Consideration of ACS}

Only the Dutch GPs registered whether they at least temporarily considered ACS during assessment (independently of their working diagnosis). This issue was stated positive in 61 (38.1\%) of 157 Dutch cases (three missing registrations on this topic).

\section{Working diagnosis}

GPs working diagnoses in most cases were of musculoskeletal origin $(26.1 \%)$, followed by psychological complaints including hyperventilation syndrome (17.0\%), cardiac ischaemic disease (14.5\%) and gastro-intestinal origin (11.2\%) (table 2). The most frequent specific- ICPC-coded-working diagnoses were L04 'chest wall related complaints' (16.7\%), R98 'hyperventilation syndrome' $(7.1 \%)$, suspicion cardiac disease not further specified (6.8\%), L99.06 'costochondritis' (6.0\%), D84 'reflux/oesophagitis', K74 'ischaemic heart disease', K74.01 'unstable angina' and psychological disorder not further specified (each 5\%). All ICPC-coded working diagnoses are available in online supplementary table a. There was no working diagnosis noted for five cases of chest pain. 
Table 2 Occurrence (in absolute numbers) of working and final diagnosis categorised per organ system, distribution (in percentages) of referral directions for each organ diagnosis and number of diagnostic tests at initial assessment by the GP and during follow-up after initial assessment by the GP

\begin{tabular}{|c|c|c|c|c|c|c|c|c|c|}
\hline & & & \multicolumn{5}{|c|}{ Referral rates ( $\%$ of all patients, $n=281$ ) } & \multicolumn{2}{|l|}{ Number of tests } \\
\hline & & & $\begin{array}{l}\text { Not } \\
\text { referred } \\
\text { by GP, \% }\end{array}$ & $\begin{array}{l}\text { Specialist, } \\
\text { not the } \\
\text { same } \\
\text { day, } \%\end{array}$ & $\begin{array}{l}\text { Coronary } \\
\text { care } \\
\text { unit, } \%\end{array}$ & $\begin{array}{l}\text { Emergency } \\
\text { department } \\
\text { otherwise, \% }\end{array}$ & Unknown, \% & $\begin{array}{l}\text { Total number of } \\
\text { tests at initial } \\
\text { assesment } \\
\text { (tests per } \\
\text { patient) }\end{array}$ & $\begin{array}{l}\text { Total number } \\
\text { of tests during } \\
\text { follow-up } \\
\text { time (tests per } \\
\text { patient) }\end{array}$ \\
\hline \multirow{8}{*}{$\begin{array}{l}\text { Absolute and relative } \\
\text { numbers of organ- } \\
\text { specific working } \\
\text { diagnosis(working } \\
\text { diagnosis known in } 276 \\
\text { of } 281 \text { cases) }\end{array}$} & $\begin{array}{l}\text { Cardiac life- } \\
\text { threatening }\end{array}$ & $\mathrm{n}=49(17.7 \%)$ & 10.2 & 38.8 & 12.2 & 30.6 & 8.2 & $41(0.84)$ & $125(2.55)$ \\
\hline & $\begin{array}{l}\text { Cardiac non-life- } \\
\text { threatening }\end{array}$ & $\mathrm{n}=48(17.4 \%)$ & 40.0 & 35.4 & 16.7 & 6.3 & 2.1 & $33(0.69)$ & $79(1.65)$ \\
\hline & Respiratory disease & $\mathrm{n}=26(9.4 \%)$ & 69.2 & 11.5 & 0 & 7.7 & 11.5 & $27(1.04)$ & $29(1.12)$ \\
\hline & $\begin{array}{l}\text { Gastro-intestinal } \\
\text { disease }\end{array}$ & $\mathrm{n}=31(11.2 \%)$ & 83.9 & 16.1 & 0 & 0 & 0 & $14(0.45)$ & $29(0.94)$ \\
\hline & $\begin{array}{l}\text { Musculoskeletal } \\
\text { disease }\end{array}$ & $\mathrm{n}=72(26.1 \%)$ & 76.4 & 11.1 & 1.4 & 4.2 & 6.9 & $23(0.32)$ & $43(0.60)$ \\
\hline & $\begin{array}{l}\text { Psychological } \\
\text { disease }\end{array}$ & $\mathrm{n}=47(17.0 \%)$ & 85.1 & 12.8 & 2.1 & 0 & 0 & $25(0.53)$ & $42(0.89)$ \\
\hline & $\begin{array}{l}\text { Other or mild } \\
\text { unspecified }\end{array}$ & $n=3(1.1 \%)$ & 100 & 0 & 0 & 0 & 0 & $1(0.33)$ & $1(0.33)$ \\
\hline & All & $n=281$ & 59.8 & 21.4 & 5.7 & 8.5 & 4.6 & $164(0.58)$ & $348(1.24)$ \\
\hline \multirow{8}{*}{$\begin{array}{l}\text { Absolute and relative } \\
\text { numbers of organ- } \\
\text { specific final diagnosis } \\
\text { (final diagnosis known in } \\
263 \text { of } 281 \text { cases) }\end{array}$} & $\begin{array}{l}\text { Cardiac life- } \\
\text { threatening }\end{array}$ & $\mathrm{n}=22(8.4 \%)$ & 18.2 & 40.9 & 13.6 & 22.7 & 4.5 & $12(0.55)$ & $53(2.41)$ \\
\hline & $\begin{array}{l}\text { Cardiac non-life- } \\
\text { threatening }\end{array}$ & $\mathrm{n}=23(8.7 \%)$ & 43.4 & 30.4 & 13.0 & 13.0 & 0 & $17(0.74)$ & $33(1.43)$ \\
\hline & Respiratory disease & $n=20(7.6 \%)$ & 55 & 20 & 0 & 5 & 20 & $19(0.95)$ & $32(1.60)$ \\
\hline & $\begin{array}{l}\text { Gastro-intestinal } \\
\text { disease }\end{array}$ & $\mathrm{n}=37(14.1 \%)$ & 67.6 & 18.9 & 8.1 & 5.4 & 0 & $20(0.54)$ & $42(1.14)$ \\
\hline & $\begin{array}{l}\text { Musculoskeletal } \\
\text { disease }\end{array}$ & $\mathrm{n}=93(35.4 \%)$ & 70.0 & 10.8 & 6.5 & 4.3 & 8.6 & $59(0.63)$ & $103(1.11)$ \\
\hline & $\begin{array}{l}\text { Psychological } \\
\text { disease }\end{array}$ & $\mathrm{n}=48(18.3 \%)$ & 75 & 18.8 & 2.1 & 4.2 & 0 & $\begin{array}{l}24 \\
(0.50)\end{array}$ & $47(0.98)$ \\
\hline & $\begin{array}{l}\text { Other or mild } \\
\text { unspecified }\end{array}$ & $\mathrm{n}=20(7.6 \%)$ & 60 & 20 & 0 & 0 & 20 & $13(0.65)$ & $38(1.90)$ \\
\hline & All & $n=281$ & 59.8 & 21.4 & 5.7 & 8.5 & 4.6 & $164(0.58)$ & 348 (1.24) \\
\hline
\end{tabular}

Registration of working diagnosis was available in 276 of the total number of 281 patients with chest pain. Registration of final diagnosis was completed in 263 of the total number of 281 patients with chest pain. Hyperventilation-although a respiratory diagnosis in the ICPC coding system-was included in 'psychological disease'. Of all 281 patients, $59.8 \%$ were not referred by their GP. The majority of the referred patients were referred for further assessment not the same day. About $14.2 \%$ of patients were referred for direct assessment in a (cardiac) emergency setting. On the right side, the distribution of the 164 diagnostic tests at initial assessment by the GP and the 348 tests after initial assessment by the GP is shown per working, respectively final organ-specific diagnosis.

$\mathrm{GP}$, General practitioner; ICPC, international classification of primary care.

\section{Life-threatening working diagnoses}

Forty-eight working diagnoses (17.1\%) were labelled as life-threatening. Of these, 7 cases $(2.5 \%)$ concerned suspected pulmonary embolism and $40(14.2 \%)$ were of cardiac ischaemic origin (6 were labelled as stable, in 34 cases suspected unstable cardiac disease or myocardial infarction was registered). In 23 cases, working diagnoses were insufficiently specified to assess a life-threatening nature.

\section{Additional diagnostic tests by GPs}

In $123 / 281$ cases of chest pain (43.8\%), one or more additional diagnostic tests (total of 164 tests) were performed by the GP at or directly after first assessment. These tests were as follows: $81(28.8 \%)$ ECGs, 59 (21.0\%) venous blood samples, 8 (2.8\%) point of care $(\mathrm{PoC})$ tests $(2 \mathrm{CRP}, 1 \mathrm{D}$-dimer, 3 Troponin PoC tests and 2 CRP and D-dimer PoC tests combined), 7 direct access chest X-rays, 1 chest CT-scan, 3 direct accessible exercise tests, 224 hours blood pressure tests and 1 abdominal ultrasound. In two cases, sublingual nitroglycerin was used as a diagnostic test (see figure 2 and table 2 for more details).

\section{Referrals by GPs}

One hundred and thirteen out of two hundred and eighty-one $(40.2 \%)$ patients with chest pain were referred after initial assessment by the GP. Sixteen out of two hundred and eighty-one $(5.7 \%)$ were referred to a coronary care unit and 24/281 (8.5\%) to another emergency department. Sixty out of two hundred and eighty-one patients $(21.4 \%)$ were referred to secondary care for assessment not the same day. Thirteen out of two hundred and eighty-one were referred to an unknown destination (table 2). Belgian GPs (49\%) had a higher referral rate than Dutch GPs $(34 \%, \mathrm{p}=0.01)$. 


\begin{tabular}{lcc}
\hline $\begin{array}{l}\text { Table } 3 \\
\text { diagnoses }\end{array}$ & \multicolumn{3}{l}{ The extent of similarity between working and final } \\
\hline Working and final diagnoses compared & 118 & 42.0 \\
\hline Equal & 104 & \\
\hline Working and final diagnoses non-life-threatening & 14 & \\
\hline Working and final diagnoses life-threatening & 75 & 26.7 \\
\hline Minor difference & 70 & \\
\hline Working and final diagnoses non-life-threatening & 5 & \\
\hline Working and final diagnoses life-threatening & 65 & 23.1 \\
\hline Major difference & 41 & \\
\hline (Life-threatening) cardiovascular diagnosis suspected, & & \\
final diagnosis mild & 21 & \\
\hline Working and final diagnoses non-life-threatening & 1 & \\
\hline Working and final diagnoses life threatening & 2 & \\
\hline Non-life-threatening disease suspected, final diagnosis & 2 & \\
life-threatening cardiovascular diagnosis & 23 & \\
\hline Missing working or final diagnoses & 281 & 100 \\
\hline Total & & \\
\hline
\end{tabular}

Working diagnosis was the GP's diagnosis at initial assessment, final diagnosis is the diagnosis after at least 30 days of follow-up, based on the clinical picture and, when appropriate, additional tests and specialists' correspondence. Terminology: 'Equal': same ICPC-code for working and final diagnose. 'Minor and major difference': ICPC-code not equal, without respectively with diagnostic consequences. In slightly more than one out of five cases (23.1\%), working and final diagnoses differed notably.

ICPC, international classification of primary care; GP, general practitioner.

\section{Follow-up after at least 1 month}

Final registration was completed in 263 of 281 chest pain cases.

\section{Hospitalisation and death}

32/263 patients (12.2\%) were hospitalised (in 13 cases, hospitalisation was less than 24 hours). In 18 cases, hospitalisation was not registered appropriately. One patient died, 18 days after initial assessment. This patient was directly referred to an

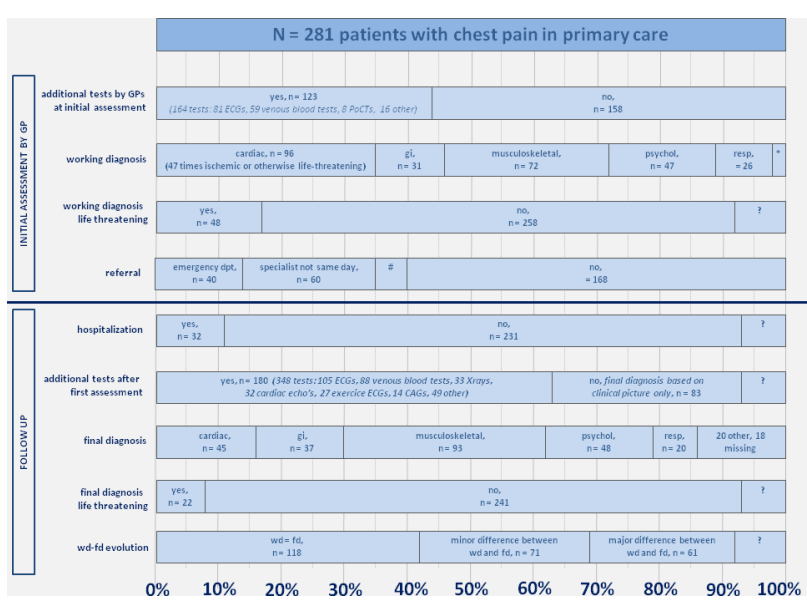

Figure 2 Diagnostic process in 281 patients with chest pain. Final registration completed in 263 patients. * Other or unknown; \#referred, destination unknown; ?unknown. CAG, coronary angiography; dpt, department; gi, gastro-intestinal ICPC-diagnosis; ICPC, international classification of primary care; PoCT, point of care test; psychol psychological ICPC-diagnosis; resp, respiratory ICPC-diagnosis. emergency setting by the GP on presentation, working as well as final diagnosis was myocardial infarction.

\section{Additional diagnostic tests during follow-up time}

In $83 / 263$ patients $(31.6 \%)$, final diagnosis was based on 'clinical picture' and follow-up only. In the remaining 180 patients, a total of 348 additional diagnostic tests were performed: 105 (39.9\%) ECG's, 88 (33.4\%) blood tests, 33 (12.5\%) chest X-rays, 32 (12.2\%) cardiac echo's, 27 (10.3\%) exercise ECG's, $14(5.3 \%)$ coronary angiographies, $10(3.8 \%)$ coronary artery CT scans, 7 (2.7\%) CT scans aimed at pulmonary embolism, 7 (2.7\%) ambulant rhythm registrations (holter monitoring) and 6 (2.3\%) gastroscopies (see figure 2 and table 2 for more details). Furthermore, eight other types of imaging techniques, four initiations or alterations of medication with a diagnostic purpose, two psychiatric tests, two abdominal ultrasound examinations, one single-photon emission computed tomography (SPECT) scan and two spirometries were performed. Tests directly performed at initial assessment by the GP are not included here (these are described above in "GPs' first assessment at presentation" of the results section).

\section{Final diagnoses}

In accordance with the working diagnoses, most final diagnoses were of musculoskeletal origin (33.1\% of cases), followed by psychological complaints including hyperventilation syndrome (17.1\%) and gastro-intestinal disease (13.2\%) (table 2). The most frequent specific - ICPC-coded-final diagnoses were L04 'chest wall related complaints' (25.6\%), R98 'hyperventilation syndrome' (8.2\%), D84 'reflux/oesophagitis' (6.4\%) and L99.06 'costochondritis' (5.0\%). All ICPC-coded working diagnoses are available in online supplementary table b. In 18 cases, no final diagnosis could be obtained.

\section{Life-threatening final diagnoses}

Final diagnoses were considered life-threatening in $22 / 263$ cases where final diagnoses were registered $(8.4 \%)$. Of these, one case of pulmonary embolism was registered $(0.38 \%)$ and the remaining 21 life-threatening cases were cardiac ischaemic (of which 5 patients were diagnosed with myocardial infarction). However, four cases were labelled as stable coronary artery disease. Therefore, 17 cases $(6.5 \%)$ of possible unstable cardiac disease or myocardial infarction were found (overall incidence $17 / 22294=0.76 \% 0$ ).

\section{Extent of similarity between working and final diagnoses}

In 258 cases, working and final diagnoses were complete (in 23 cases working or final diagnoses were missing). In 68.7\% of cases, the ICPC-coding of working and final diagnoses was exactly equal or ICPC-coding differed minimally without diagnostic consequences. There was a major difference between the working and final diagnoses in 65 (23.1\%) cases (table 3). Of these, in 41 cases, there was a (life-threatening) cardiovascular diagnosis suspected and a mild final diagnosis was reported (leading to 21 referrals to an emergency service, 11 referrals to a specialist at a later time and 9 cases where GPs performed one or more diagnostic test without referral). In 21 cases, working and final diagnoses differed, but were all non-life-threatening diseases. In one case, working and final diagnoses differed, but were all life-threatening diseases. In two cases $(0.7 \%$ of all chest pain patients), a mild working diagnosis was suspected, whereas the final diagnosis was a life-threatening cardiovascular diagnosis. The working and final diagnoses in these two patients were 
atrial fibrillation and ischaemic heart disease in the first case and pneumonia and acute myocardial infarction in the second case. Both were not referred at initial assessment.

\section{DISCUSSION}

In our current survey, we found that $1.26 \%$ of all GPs consultations, home visits and telephone contacts during office hours, were related to chest pain. This is comparable with earlier presented data on incidence of chest pain (estimated to be $0.7 \%-2.7 \%) .{ }^{1-3}$ Therefore, our random survey appears to be representative, the SEM (0.11) was consistently low. In 48 cases, a life-threatening disease was suspected as a working diagnosis after complete assessment by the GP. The final diagnosis was labelled as life-threatening in 22 patients, 17 of which considered unstable cardiac disease or myocardial infarction, corresponding with an incidence rate of 0.76 per 1000 contacts in primary care. All together, $40.2 \%$ of patients were referred to secondary care facilities as a consequence of their visiting the GP for chest pain.

\section{Causes of chest pain}

Most frequently found working and final diagnosis was 'chest wall related complaints'. Other regularly diagnosed underlying causes of chest pain were hyperventilation syndrome, reflux or oesophagitis and costochondritis. Life-threatening diseases are found in $8.4 \%$ of patients with chest pain in primary care. An ACS as a final diagnosis occurred in 6.5\%. All these findings were in agreement with international literature although the percentage of ACS was slightly higher than the 1.5\%$3.6 \%$ recently published in a meta-analysis. ${ }^{414-18}$

\section{Patient numbers}

The low incidence of unstable cardiac ischaemic conditions of $6.5 \%$ as reported, probably reflects the low-risk selection of patients with chest pain faced by GPs. However, absolute numbers of chest pain patients with severe underlying causes are relevant. For example, in the Netherlands, an annual number of consultations of 68.5 million is carried out by GPs (see www. cbs.nl). Therefore, our data suggest that every year in the Netherlands, 863100 consultations (1.26\%) are about chest pain. During 328841 consultations (38.1\%), ACS is at least briefly considered as an underlying cause. After 122560 consultations $(14.2 \%)$, referral to an emergency department is made. In 72500 consultations (8.4\%), a life-threatening disease is diagnosed and in 790560 consultations (91.6\%), the final outcome is not life-threatening. In 56102 consultations (6.5\%), an unstable cardiac ischaemic disease is the final outcome. Thus, among the frequently occurring conditions where urgent intervention is not demanded, severe cardiac disease is far from impossible.

\section{How do GPs assess patients with chest pain?}

The awareness of a possible severe cause of chest pain seems to be reflected in the way patients with chest pain are approached by GPs. The ratio between referral to secondary care $(40.2 \%)$ and a life-threatening outcome $(8.4 \%)$ is approximately $5: 1$. The complex distinction between a mild and a severe underlying cause of chest pain is further illustrated by the 512 additional tests performed at initial assessment and during follow-up time in our population of 281 patients with chest pain. These tests covered a wide variety of diagnostic means, however, recording an ECG was the most used diagnostic test (186 times).

In $23.1 \%$ of all chest pain cases, a major difference was found between the working and final diagnoses, in most cases due to a mild final diagnosis following a severe working diagnosis. However, two life-threatening final diagnoses were initially assessed as non-life-threatening. This percentage of $23.1 \%$ is relatively high when compared with $8 \%$ found in a previous study. ${ }^{19}$ However, our classification 'major difference' was not only used in cases where a relevant diagnosis was missed by a GP but also used in cases where a working diagnosis lead to additional diagnostic tests to rule out certain conditions.

\section{Strengths and weaknesses}

This study is performed in primary care, which is the major strength. A participating GP recorded on average 95 patient contacts per week, including consultations in the office, home visits and telephone contacts. This is in line with the expected number, as a result we assume that the registration was approximately complete. Moreover, this study examined a part of chest pain in primary care where little is known about, namely the diagnostic steps taken by the GP. Therefore, this study contains information about the working diagnosis, final diagnosis and the process in between. However, information about 18 final diagnoses of patients with chest pain (6.4\%) were missing. Besides, our registry did not cover a full year. As a result, not all seasons (and associated possible fluctuations in incidence of chest pain) were covered representatively. $0.5 \%$ of all Belgian and Dutch GPs participated, providing a reliable survey, however larger studies would be of added value, in order to further address geographic and other variation between GP practices.

In cases where a GP did not refer a patient initially and where during the follow-up no additional contact took place, working and final diagnoses were both assessed by the GP. We cannot

\section{Key messages}

\section{What is already known on this subject?}

Of all consultations in primary care, a considerable $0.7 \%-2.7 \%$ is about chest pain. Less is known about what diagnostic means are performed in this population and about agreement between initial working and final diagnoses after 30 days. Final diagnoses have been studied earlier, but might be subject to change due to improved diagnostic tests (mainly high-sensitive troponin assays).

\section{What might this study add?}

$1.26 \%$ of all general practitioner (GP) consultations were about chest pain, a large number of diagnostic tests were performed in these patients with chest pain by GPs and specialists ( 512 diagnostic tests in 281 patients) and the most frequently determined final diagnosis was chest wall-related complaints in $93 / 281$ cases $(33 \%)$. Judging by the ratio between number of referred patients ( $40.2 \%$ of all cases) and the number of lifethreatening final diagnoses (8.4\%) on the one hand, and the low number of missed cases of severe disease (2/281 or $0.7 \%$ ) on the other hand, GPs safely overestimate the risk of life-threatening diseases at initial assessment.

\section{How might this impact on clinical practice?}

Since patients with chest pain in primary care undergo a wide variety of additional diagnostic tests, clinical decision rules or point of care testing could add to reduction in costs and discomfort. GPs and cardiologists will profit from an up-to-date overview of frequent and rare causes of chest pain in primary care patients. 
exclude possible missed cases of ischaemic cardiac disease among these patients because no expert panel using troponin measurements as a gold standard was part of the study protocol. However, our aim was to observe the clinical course in patients with chest pain in primary care, rather than detect subclinical cases of ischaemia.

\section{Conclusion}

A significant number of patients with chest pain primarily contact their GP. On the one hand, one could say that in $91.6 \%$ of these cases, a life-threatening condition is absent and the pre-consultation probability of an unstable ischaemic cardiac disease in case of chest pain is no more than $6.5 \%$. On the other hand, the overall occurrence and burden of chest pain patients in primary care is of important clinical significance. This is illustrated by the numbers and percentages we found as an answer to the seven issues, we described in our introduction as the aim of this study. First, (1) $1.26 \%$ of consultations in primary care is about chest pain. Furthermore, concerning the population of 281 patients with chest pain, (2) ACS is at least temporarily suspected in $38.1 \%$, (3) 512 diagnostic tests are performed, (4) 40.2\% are referred for assessment in secondary care facilities, (5) working diagnosis are life-threatening diseases in $17.1 \%$, (6) final diagnoses are life-threatening diseases in $8.4 \%$, and (7) GPs tend to take severe diseases in account at initial assessment, probably to be on the safe side and rule out disease directly after assessment, rather than miss life-threatening diagnoses. In the future, GPs might benefit from safe prediction rules and/or fast accessible tests to enhance efficiency in this demanding area of primary care.

Acknowledgements We sincerely thank the GPs who registered their activities and thereby enabled this analysis.

Funding The study is funded by means of an unrestricted grant by FABPulous $B V$, the company that develops point-of care H-FABP-tests. FABPulous BV agreed not to interfere with data collection, data management and analysis of data. Publication of possible unfavorable outcome of our study was guaranteed.

Competing interests JFCG is chief scientific officer (CSO) at FABPulous BV. The remaining authors report no conflicts of interest. The authors alone are responsible for the content and writing of the paper.

Patient consent Not applicable.

Provenance and peer review Not commissioned; externally peer reviewed. (c) Article author(s) (or their employer(s) unless otherwise stated in the text of the article) 2017. All rights reserved. No commercial use is permitted unless otherwise expressly granted.

\section{REFERENCES}

1 Nilsson S, Scheike M, Engblom D, et al. Chest pain and ischaemic heart disease in primary care. Br J Gen Pract 2003;53:378-82.

2 Verdon F, Herzig L, Burnand B, et al. Chest pain in daily practice: occurrence, causes and management. Swiss Med Wkly 2008;138:340-7.

3 Bösner S, Becker A, Haasenritter J, et al. Chest pain in primary care: epidemiology and pre-work-up probabilities. Eur J Gen Pract 2009;15:141-6.

4 Haasenritter J, Biroga T, Keunecke C, et al. Causes of chest pain in primary care--a systematic review and meta-analysis. Croat Med J 2015;56:422-30.

5 Bruins Slot MH, Rutten FH, van der Heijden GJ, et al. Diagnostic value of a hearttype fatty acid-binding protein (H-FABP) bedside test in suspected acute coronary syndrome in primary care. Int J Cardiol 2013;168:1485-9.

6 Buntinx F, Mant D, Van den Bruel A, et al. Dealing with low-incidence serious diseases in general practice. Br J Gen Pract 2011;61:43-6.

7 Reimer KA, Jennings RB. The "wavefront phenomenon" of myocardial ischemic cell death. II. Transmural progression of necrosis within the framework of ischemic bed size (myocardium at risk) and collateral flow. Lab Invest 1979;40:633-44.

8 Goodacre S, Cross E, Arnold J, et al. The health care burden of acute chest pain. Heart 2005;91:229-30.

9 Body R, Carley S, Wibberley C, et al. The value of symptoms and signs in the emergent diagnosis of acute coronary syndromes. Resuscitation 2010;81:281-6.

10 Rutten $\mathrm{FH}$, Kessels AG, Willems FF, et al. Electrocardiography in primary care; is it useful? Int J Cardiol 2000;74:199-205.

11 Swap CJ, Nagurney JT. Value and limitations of chest pain history in the evaluation of patients with suspected acute coronary syndromes. JAMA 2005;294:2623-9.

12 Bruyninckx R, Aertgeerts B, Bruyninckx P, et al. Signs and symptoms in diagnosing acute myocardial infarction and acute coronary syndrome: a diagnostic meta-analysis. Br J Gen Pract 2008:58:1-8.

13 Hani MA, Keller H, Vandenesch J, et al. Different from what the textbooks say: how GPs diagnose coronary heart disease. Fam Pract 2007;24:622-7.

14 Svavarsdóttir AE, Jónasson MR, Gudmundsson GH, et al. Chest pain in family practice. diagnosis and long-term outcome in a community setting. Can Fam Physician 1996;42:1122-8

15 Klinkman MS, Stevens D, Gorenflo DW. Episodes of care for chest pain: a preliminary report from MIRNET. J Fam Pract 1994;38:345-52.

16 Buntinx F, Knockaert D, Bruyninckx R, et al. Chest pain in general practice or in the hospital emergency department: is it the same? Fam Pract 2001;18:586-9.

17 Bösner S, Haasenritter J, Becker A, et al. Ruling out coronary artery disease in primary care: development and validation of a simple prediction rule. CMAJ 2010;182:1295-300.

18 Bösner S, Becker A, Hani MA, et al. Chest wall syndrome in primary care patients with chest pain: presentation, associated features and diagnosis. Fam Pract 2010;27:363-9.

19 Buntinx F, Truyen J, Embrechts P, et al. Chest pain: an evaluation of the initial diagnosis made by 25 flemish general practitioners. Fam Pract 1991;8:121-4. 